\title{
MORPHOMETRIC STUDY OF CEPHALO-FACIAL INDICES AMONG BINI CHILDREN IN SOUTHERN NIGERIA \\ ${ }^{* 1}$ OMOTOSO, D. R., ${ }^{2}$ OLANREWAJU, A. J., ${ }^{1}$ OKWUONU, U.C., ${ }^{1}$ ADAGBOYIN, O., ${ }^{1}$ BIENONWU, E. 0.
}

${ }^{1}$ Department of Anatomy, College of Health Sciences, Igbinedion University, Okada, Edo State, Nigeria ${ }^{2}$ Department of Anatomy, College of Health Sciences, Babcock University, Ilisan-Remo, Ogun State, Nigeria

* Correspondence to Dr. D.R. Omotoso Department of Anatomy, College of Health Sciences, Igbinedion University, Okada, Edo State, Nigeria. @ dayohmts@gmail.com. Phone: +2348034779886

\section{ABSTRACT}

Cephalometry is an important branch of anthropometry which involves the morphological study of structures present in the human head or scientific measurement of the dimensions of the head. Some of the most important cephalometric parameters include the length/height and breadth/width of the head, the face and the nose as well as their respective indices. These cephalometric parameters are vital in the description of variation which is a common phenomenon that characterizes human physiognomy. They are also useful in the description of human inter-racial and intra-racial similarities both within and across gender. This study involved 450 Bini children (235 males and 215 females) between ages 5-12 years. The length and width of the head and face of each subject was measured between the appropriate anatomical landmarks using spreading and sliding calipers. The measurements were used to calculate the cephalic and facial indices for each subject. The result showed sexual variation in both cephalic and facial indices among the Bini children with the males having higher values than the females. Also, the result of this study showed that prevalence of brachycephalic head type among both male (51.1\%) and female (49.8\%) Bini children. The mesoproscopic face type was the most prevalent face type among both male (62.6\%) and female (47.4\%) Bini children. The cephalo-facial indices are vital in demonstrating similarity and variation in physical morphologies of individuals or group of people of different ethnicity, races, gender and geographical locations.

Keywords: Cephalometry, Cephalic index, facial index, Bini children, Nigeria

\section{INTRODUCTION}

Anthropometry can be defined as the art and science of measurements of physical dimensions, mass and strength of parts or whole of human body especially in terms of bone, muscle and adipose tissue (Del Prado-Lu, 2007; Varalakshmi et al, 2017). It is derived from Greek words "Anthropos" (which means "Man") and "Metron" (which means "to measure"). Anthropometric studies have employed diverse techniques to measure and produce standard values for skeletal, dental and soft tissue structures for different human population (Argyropouloss and Sassouni, 1989; Del PradoLu, 2007). Anthropometric results from these studies have important applications in peadiatrics, forensic medicine, plastic surgery, oral surgery, diagnostic and treatment planning (William et al, 1995; Golalipour et al, 2003; Heidari et al, 2004). They are also used to make comparison between clinical patients and normal populations, to determine health status, body composition or physical fitness or performance levels of individuals and in physical or industrial ergonomics (Del Prado-Lu, 2007; Andreasi, et al, 2010; Abellan-Aynes and Alacid, 2016; Sevinc and Yilmaz, 2017). Generally, the anatomy of human head and face has been described to provide primary basis for description and identification of humans especially during accidental cases such as burns, traffic accident, 
plane crash, natural disasters etc (Jasuja and Singh, 2004; Hennessy et al, 2005). An important branch of anthropometry which involves the morphological study of structures present in the human head or scientific measurement of the dimension of the head is known as cephalometry (Grau et al, 2001; Elfeghi et al, 2004). Some of the most important cephalometric parameters include length/height and breadth/width of the head, the face and the nose as well as their respective indices. These cephalometric parameters are vital in the description of variation which is a common phenomenon that characterizes human physiognomy. They are also useful in the description of human inter-racial and intra-racial similarities both within and across gender (Golalipour et al, 2003; Omotoso et al, 2011; Oludiran et al, 2012). In essence, anthropometric studies involving the head and face have diverse applications and uses. Therefore, continuous cephalometric studies among different human populations are required to determine baseline cephalometric values for individual population and basis for comparative studies between different populations. This study was done to evaluate the cephalo-facial morphology of Bini male and female children in Southern Nigeria and to describe sexual dimorphism among the study population.

\section{MATERIALS AND METHOD}

For this study, 450 Bini children comprising of 235 males and 215 females between ages 5-12 years were randomly selected to represent the larger population. The length and width of the head and face of each subject was measured between the appropriate anatomical landmarks that define them (i.e. the head length = distance between glabella and opisthocranion; the head width = distance between right and left parietal prominences; the facial length = distance between nasion and gnathion and the morphological facial width/bizygomatic width = distance between right and left zygia). All measurements were taken using spreading and sliding calipers, with the subject in a sitting and

Table 1: Classification of head types based on the cephalic index

\begin{tabular}{|l|c|}
\hline \multicolumn{1}{|c|}{ CLASSES } & RANGE \\
\hline Dolicephalic (long and narrow) & $70-74.9$ \\
\hline Mesocephalic (average shape) & $75-79.9$ \\
\hline Brachycephalic (broad and short) & $80-84.9$ \\
\hline $\begin{array}{l}\text { Hyperbrachycephalic (very broad } \\
\text { and short) }\end{array}$ & $\geq 85$ \\
\hline
\end{tabular}

relaxed position and the head in an anatomical position. The measurements were recorded and used to calculate the cephalic and facial indices using the following equations (Heidari et al, 2004; Golalipour et al, 2003):

Cephalic Index $=$ Maximum Head Breadth X 100 Maximum Head Length

Facial Index $=$ Morphological Facial Length X 100 Facial Width

The morphological classification of head and face among the study population on the bases of their cephalic and facial indices was derived using the following Tables 1 and 2 (Heidari, et al., 2006; Shah and Koriala, 2015).

Table 2: Classification of face types based on the facial index

\begin{tabular}{|l|c|}
\hline \multicolumn{1}{|c|}{ CLASSES } & RANGE \\
\hline Hypereuryproscopic (very broad) & $<80$ \\
\hline Euryproscopic (broad) & $80-84.9$ \\
\hline Mesoproscopic (round) & $85-89.9$ \\
\hline Leptoproscopic (long) & $90-94.9$ \\
\hline Hyperleptoproscopic (very long) & $\geq 95$ \\
\hline
\end{tabular}

\section{RESULTS}

The mean cephalic index for Bini male and female children was $81.58 \pm 1.96$ and $81.23 \pm$ 1.56 respectively. The mean facial index for Bini males and females was $86.87 \pm 2.15$ and 84.88 \pm 2.12 respectively. This showed that the cephalic and facial index values were higher among the Bini males than the Bini females (Figures 1 and 2). The morphological 
classification of the head types showed the prevalence of the brachycephalic head type among both male $(51.1 \%)$ and female $(49.8 \%)$ Bini children while the least common head type was hyperbrachycephalic (11.5\%) and (13.9\%) respectively. There was no dolicephalic head type observed among the Bini children (Figures 3 and 4). The morphological classification of the face types showed the prevalence of the mesoproscopic face type among both male $(62.6 \%)$ and female (47.4\%) Bini children while the least common type were leptoproscopic $(11.9 \%)$ and hypereuryproscopic (3.3\%) respectively. There was no hyperleptoproscopic face type observed among the Bini children (Figures 5 and 6).

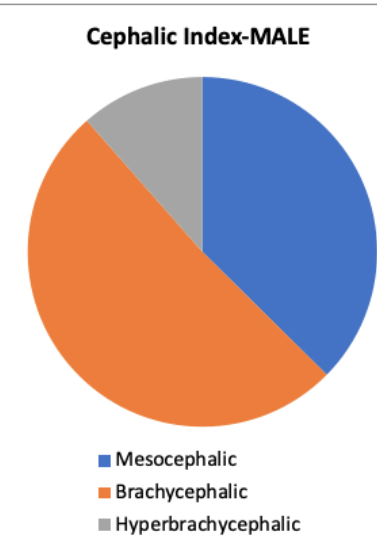

Figure 3: Chart showing

Figure 1: The mean cephalic index values among Bini male and female children Figure 2: The mean facial

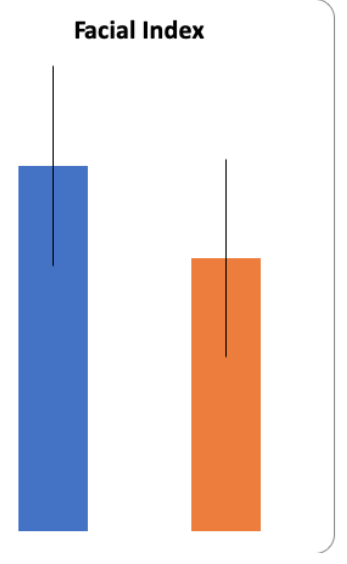
index values among Bini male and female children distribution of head types using cephalic index of Bini male children

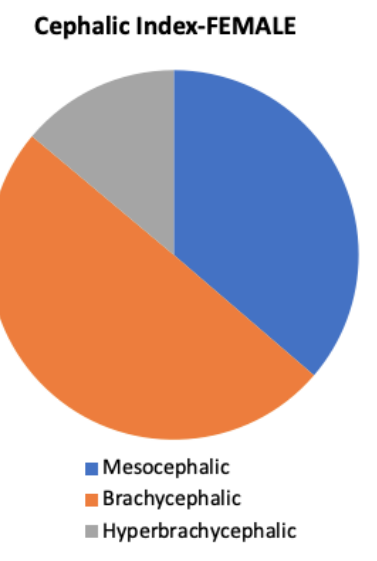

Figure 4: Chart showing distribution of head types using cephalic index of Bini female children

Table 3: Cephalic and Facial Indices for Bini Male and Female Children

\begin{tabular}{|l|c|c|c|c|}
\hline \multirow{2}{*}{ VARIABLES } & \multicolumn{2}{|c|}{ MALES (235) } & \multicolumn{2}{c|}{ FEMALES (215) } \\
\cline { 2 - 5 } & Mean \pm S.E.M. & S. D & Mean \pm S.E.M & S. D \\
\hline Cephalic Index & $81.58 \pm 1.96$ & 2.87 & $81.23 \pm 1.56$ & 2.56 \\
\hline Facial Index & $86.87 \pm 2.15$ & 2.64 & $84.88 \pm 2.12$ & 3.91 \\
\hline
\end{tabular}

Table 4: The Frequency and \% of the head types among the Bini Male and Female Children

\begin{tabular}{|l|c|c|c|c|}
\hline \multirow{2}{*}{ CLASSES } & \multicolumn{3}{|c|}{$\begin{array}{c}\text { MALES } \\
\text { (235) }\end{array}$} & \multicolumn{2}{c|}{ FEMALES (215) } \\
\cline { 2 - 5 } & $\mathrm{n}$ & $\%$ & $\mathrm{n}$ & $\%$ \\
\hline Dolicephalic & - & - & - & - \\
\hline Mesocephalic & 88 & 37.4 & 78 & 36.3 \\
\hline Brachycephalic & 120 & 51.1 & 107 & 49.8 \\
\hline Hyperbrachycephalic & 27 & 11.5 & 30 & 13.9 \\
\hline
\end{tabular}




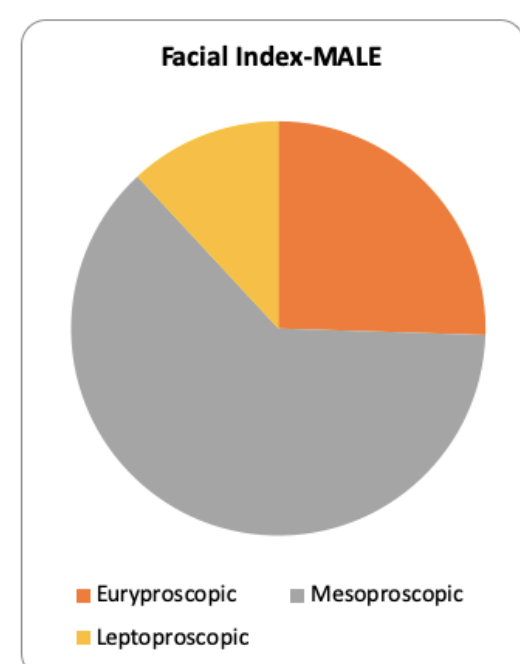

Figure 5: Chart showing distribution of face types using facial index of Bini male children

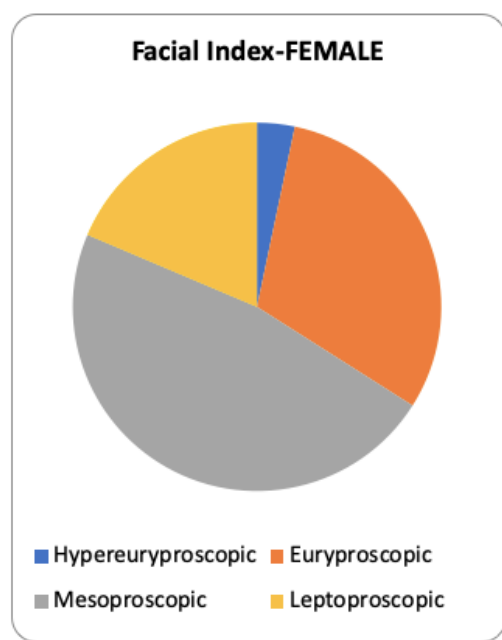

Figure 6: Chart showing distribution of face types using facial index of Bini female children

Table 5: The Frequency and \% of the face types among the Bini Male and Female Children

\begin{tabular}{|l|c|c|c|c|}
\hline \multirow{2}{*}{ CLASSES } & \multicolumn{2}{|c|}{ MALES (235) } & \multicolumn{2}{c|}{ FEMALES (215) } \\
\cline { 2 - 5 } & Frequency & $\%$ & Frequency & $\%$ \\
\hline Hypereuryproscopic & - & - & 7 & 3.3 \\
\hline Euryproscopic & 60 & 25.5 & 66 & 30.7 \\
\hline Mesoproscopic & 147 & 62.6 & 102 & 47.4 \\
\hline Leptoproscopic & 28 & 11.9 & 40 & 18.6 \\
\hline Hyperleptoproscopic & - & - & - & - \\
\hline
\end{tabular}

\section{DISCUSSION}

Variation in physical morphology is an important phenomenon in the description of human population (Omotoso, et al, 2011). This morphological variation can be quantified, analyzed and described by using anthropometric measurements or parameters of body parts (such as head and face) that characteristically define the identity of an individual or groups of people (tribes or race). Geographical location has been described as a vital tool in description of population differences and craniofacial morphology offers important anthropometric indicators to make such description (Ribot 2004; Shah and Koriala, 2015). According to the result of this study, the cephalic and facial index values showed sexual dimorphism among adult Bini male and female children with the males having higher values than the females. Comparatively, both indices showed similarity and variation from the values obtained from studies among other ethnic groups in different geographical locations. The cephalic index obtained from this study was significantly lower than value (88.10) obtained among the Ovu community in Delta State but were significantly higher than those obtained among the Kanuri male and female neonates (70.03 and 77.15 respectively) and Babur/Bura male and female neonates (73.60 and 77.23 respectively) in Nigeria (Enahowo and Igbigbi, 2006; Garba et al, 2008). Mibodi and Frahani (1996) reported a significantly higher cephalic index (87.50 \pm 6.4) among the Iranians; Lobo et 
al, (2005) also reported higher values among male (83.1) and female (84.6) Nepalese (Gurung community). The prevalence of brachycephalic head type among both Bini male and female children was similar to those reported among the Urhobo and Itsekiri tribes but at variance to the prevalence of dolicephalic and mesocephalic head types observed among the Kanuri and Babur/Bura tribes in Nigeria (Oladipo et al, 2006; Garba et al, 2008). Jordaan, (1976), Lobo et al, (2005) and Pandey (2006) also reported the prevalence of brachycephaly among South Africans, Nepalese (Gurung community) and Indians (Onge tribe) respectively. However, the dominant head type among the Iranians was hyperbrachycephalic type (Mibodi and Frahani, 1996).

The facial index values from this study was similar to results obtained among the three major tribes in Nigeria - Yoruba (85.06 \pm 3.64$)$, Igbo $(86.56 \pm 4.08)$ and Hausa (87.67 \pm 3.69$)$ in a study by Ewunonu et al, (2006). The prevalence of mesoproscopic face type among the Bini children was similar to results obtained among the three major tribes (Yoruba, Hausa and Igbo) but at variance to the prevalence of Conflict of Interest: None hypereuryproscopic face type observed among some minor tribes (Kanuri and Babur/Bura) in Nigeria (Ewunonu et al, 2006; Garba et al, 2008). The study by Pandey (2006) showed the hypereuryproscopic face type as the most common among the Onge males (59.29\%) and females (76.92\%) in India. Heidari et al, (2006) reported the prevalence of euryproscopic face type among the Sistani (Fars) and Baluch women in Iran while Golalipour et al, (2003) showed that the Iranian Fars (Gorgani and Turkaman) male infants are mostly hypereuryproscopic. Based on cephalic and facial indices, this study showed brachycephaly and mesoproscopy as the current phenomena in the cranial and facial morphologies of the Bini children in Nigeria.

In conclusion, the cranial and facial forms and morphologies showed diversity among human population. Therefore, the cranial and facial indices are vital in demonstrating similarity and variation in physical morphologies of individuals or group of people of different ethnicity, races, gender and geographical locations.

\section{REFERENCES}

1. Abellán-Aynés O, Alacid F. 2015. Anthropometric profile, physical fitness and differences between performance level of Parkour practitioners. Arch Med Deporte, 33(5): 312 - 316.

2. Andreasi V, Michelin E, Rinaldi AEM, Burini RC. 2010. Physical fitness and associations with anthropometric measurements in 7 to 15 -year-old school children. Journal de pediatria, 86(6): $497-502$.

3. Argyropoulus E, Sassouni V. 1989. Comparison of the dentofacial patterns for native Greek and American - Caucasian adolescents. Am. J. Orthodontics and dentofacial Orthopedics, 95: 238 49.

4. Broadbent BH. 1931. A new X - ray technique and its application to orthodontics. Angle Orthod, 1: $45-66$.

5. Del Prado-Lu JL. 2007. Anthropometric measurement of Filipino manufacturing workers. International Journal of Industrial Ergonomics, 37: 497 - 503. Doi:10.1016/j.ergon.2007.02.004

6. El-feghi I, Sid-Ahmad MA, Ahmadi M. 2004. Automatic localization of craniofacial landmarks for assisted cephalometry. Pattern Recognition, 57: $609-21$.

7. Enaohwo TM, Igbigbi PS. 2006. Cephalix index in Ovu community of Delta state. Abstract of Anat. Soc. Nigeria 3: 26.

8. Ewunonu EO, Ekanem TB, Aligekwe AU, Igiri AO, Igbigbi PS, Obikili EN, Egwu OA, Eteudo AN. 2006. Comparative study on the Facial Indices of the three major tribes in Nigeria. Abstract of Journal of Anat. Soc of Nig. 
9. Garba H, Numan AI, Mishara IG. 2008. Craniofacial classification of normal newborns in Maiduguri metropolis, Nigeria. International Journal of Morphology, 26(2): 407 - 410.

10. Golalipour MJ, Haidari K, Jahanshahi M, Farahani RM. 2003. The shapes of Head and Face in normal male newborns in South - East of Capsian Sea (Iran - Gorgan). J. Anat. Soc. India, 52(1): $28-31$.

11. Grau V, Alcaniz M, Juan MC, Monserrat C, Knoll C. 2001. Automatic localization of craniofacial landmarks. Journal of Biomedical Informatics, 54: $146-56$.

12. Heidari Z, Mahmoudzadeh-Sagheb H, Mohamadi M, Noori-Mugahi MH, Arab A. 2004. Cephalic and Proscopic indices: Comparison in one - day newborn boys in Zahedan. J. Fac. Med, 62: 156 $-65$.

13. Heidari Z, Sagheb HM, Mugahi MN. 2006. Morphological evaluation of Head and Face in $18-25$ years old women in South East of Iran. J. Med. Sci, 6(3): $400-404$.

14. Hennessy RJ, Mclearie S, Kinsella A. 2005. Facial surface analysis by 3D laser scanning and geometric morphometrics in relation to sexual dimorphism in cerebral - craniofacial morphogenesis and cognitive function. Journal of Anatomy, 207: 285 - 293.

15. Jasuja OP, Singh G. 2004. Estimation of stature from hand and phalangeal length. Journal of Indian Academy of Forensic Medicine, 26(3): 100 - 106.

16. Jordaan HV. 1976. Neonatal and maternal cranial form. S. Afr. Med. J, 4: $2060-2068$.

17. Lobo SW, Chandrashekhar TS, Kumar S. 2005. Cephalic Index of Gurung community of Nepal An anthropometric Study. Kathmandu University Medical Journal, 3(11): 263 - 265.

18. Mibodi IMA, Frahani MR. 1996. Study of normal range of anatomical dimensions of one- day old newborn by cephalometry. Journal of Medical Council of Islamic Republic of Iran, 14(1): 1 - 8.

19. Oladipo GS, Akparobore E, Olofe JE. 2006. Anthropometric comparison of cephalic index between the Urhobo and Itsekiri ethnic groups of Delta State, Nigeria. Abstract of J. Anat. Soc. Nig.

20. Oludiran OO, Omotoso DR, Sakpa CL. 2012. Nasofacial Indices among Children in Southern Nigeria African Journal of Biomedical Research, 15(2): 141 - 143.

21. Omotoso DR, Oludiran OO, Sakpa CL. 2011. Nasofacial Anthropometry of Adult Bini Tribe in Nigeria. African Journal of Biomedical Research, 14 (3): $219-221$.

22. Pandey AK. 2006. Cephalo - facial variation among Onges. Kamla - Raj Anthropologist, 8(4): 245 $-249$.

23. Ribot I. 2004. Differentiation of modern sub-Saharan African populations: Craniometric interpretations in relation to geography and history. Bulletins et Mémoires de la Sociétéd'Anthropologie de Paris, 16: 143 - 165.

24. Sevinc D, Yilmaz V. 2017. The Relationship between Anthropometric Properties and Physical Performance Levels of 9-12 Years Old Taekwondoists. International Journal of Science Culture and Sport, 5(4): 285 - 292. Doi: 10.14486/IntJSCS685

25. Shah S, Koirala S. 2015. Role of Craniofacial Anthropometry in Medical Science. International Invention Journal of Medicine and Medical Sciences, 2(4): $44-48$.

26. Varalakshmi VS, Mehmood S, Gopichand PVV, Kumar D. 2017. Anthropometry: As A Tool in Learning Living Anatomy. Scholars Journal of Applied Medical Sciences, 5(5): 1938 - 1944.

27. Williams PL, Bannister LH, Berry MM, Collins P, Dyson M, Dussak JE, Ferguson MWJ. 1995. Gray's Anatomy: Skeletal System, 38 ${ }^{\text {th }}$ Edition, Churchill Livingstone, Philadelphia. Pages: $607-612$. 